\title{
Tidal Discharge Asymmetry in a Salt Marsh Drainage System
}

John D. Boon

Virginia Institute of Marine Science, boon@vims.edu

Follow this and additional works at: https://scholarworks.wm.edu/vimsarticles

Part of the Environmental Sciences Commons

\section{Recommended Citation}

Boon, John D., "Tidal Discharge Asymmetry in a Salt Marsh Drainage System" (1975). VIMS Articles. 688. https://scholarworks.wm.edu/vimsarticles/688 


\title{
Tidal discharge asymmetry in a salt marsh drainage system ${ }^{1,2}$
}

\author{
John D. Boon III \\ Virginia Institute of Marine Science, Gloucester Point 23062
}

\begin{abstract}
Tidal discharge and area-averaged current spced were measured over complete tidal cycles at the entrance to a salt marsh drainage system noar Wachapreague, Virginia. A pronounced asymmetry in curves of discharge and current speed through time was observed which can be simulated by a model incorporating scmidiurnal tides and "overtides" in conjunction with marsh and channel storage relationships. As a persistent feature in marsh channel flow relationships, the asymmetry, along with an apparent difference in flood and ebb maxima, may have a systematic, long term influence on the net transport of suspended matter entering and leaving natural marshes.
\end{abstract}

This paper presents the results of a series of detailed flow measurement made at the entrance to a small tidal marsh channel and describes a marked asymmetry or distortion in the curves of discharge and current speed, found to be typical of this type of system. The asymmetry observed ropresents a significant departure from the nearly sinusoidal curves found in many other tidal waterways, common examples of which are illustrated in tidal current prediction tables. For a simple sine curve, extreme valucs occur midway between the zero or slack water crosisings. For the system in question, flood and ebb extrema typically occur at botween 1 and $2 \mathrm{hr}$ before and after the time of high water slack (slack before ebb), or some 4 to 5 hr away from low water slack (slack before flood) in a normal cycle of slightly more than 12-hr duration. There are other examples (Myrick and Leopold 1963; Pestrong 1965) but I am not aware that the cause of the distortion has ever bcen satisfactorily explained. I offer an explanation here with the aid of a model simulating marsh channel hydraulics, or more properly, marsh and channel conveyance-storage relationships.

\footnotetext{
${ }^{1}$ Contribution No. 630 Virginia Institute of Marinc Science.

2 This work was partly supported by the RANN program of the National Science Foundation with initial support from NSF doctoral dissertation grant GA 28545. This paper contains portions of a Ph.D. thesis submitted to the College of William and Mary, Williamsburg, Virginia.
}

The significance of tidal current asymmetries in relation to the transport of suspended matter was emphasized by Postma (1961, 1967) and Groen (1967) in the course of their work in the Dutch Wadden Sea. Speaking primarily of the tidal flat and channel complex in the western part of the Wadden Sea, Postma illustrated a pronounced current asymmetry for flow confined during part of each cycle to a tidal channel and extending the remainder of the time over a tidal flat. In this instance, the current maxima were shifted toward the time of low water slack, just opposite to the shift mentioned above for marsh channels. Croen later prosented a thcoretical model incorporating the asymmetry observed by Postma to show how a residual (nontidal) transport of suspended sediment could occur in a channel experiencing no net transport of water over a completc tidal cycle. The direction of the residual predicted by the model was landward, or toward the inner reaches of the Wadden Sea as had long been inferred (Postma 1954; Van Straaten and Kuenen 1957).

In other areas such as the east coast of the United States, the question of residual sediment transport in a variety of tidal waterways remains problematic (Meade 1969, 1974; Oostdam 1971; Boon 1974). Few field studies have been made that incorporate adequate temporal and spatial measures of suspended scdiment concentration and current velocity, the principal variables in the transport equation. Added to this is the uncertainty of seasonal ef- 


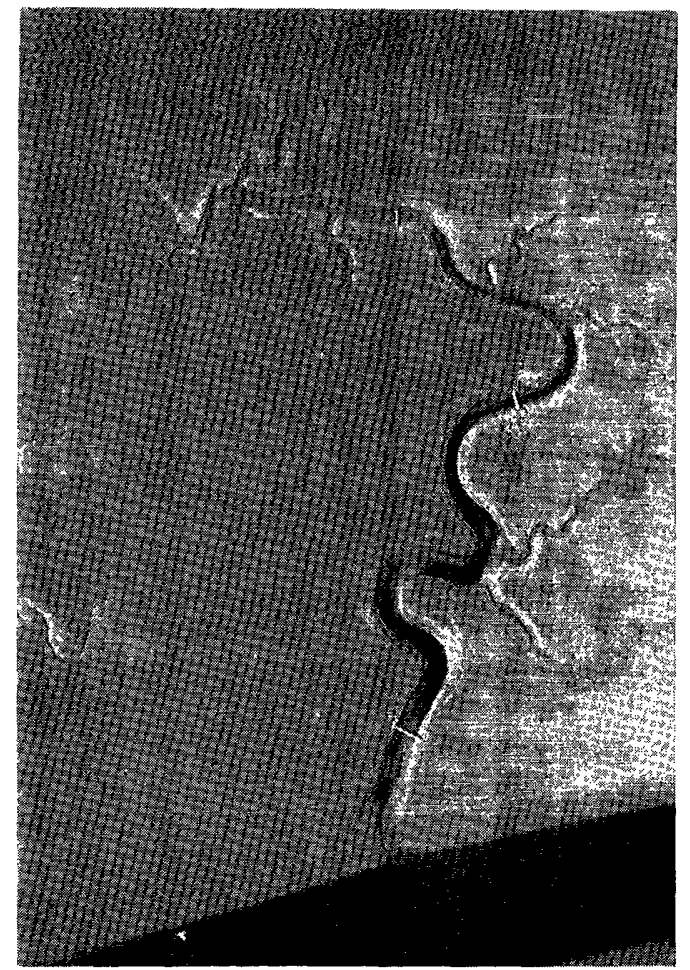

Fig. 1. Black and white infrared photograph of Little Fool Creek during low tide, 6 April 1973. Distance between left bank corners of middle and lower bridge spans is $143 \mathrm{~m}$.

fects and extreme weather events. In situations of this type where the ultimate answers are elusive, it seems appropriate to increase onc's understanding of individual physical processes and weigh their effects carefully. Local variations in tidal flow relationships are such processes.

I am indebted to R. J. Byrne for critical reading of the manuscript and to $\mathrm{G}$. Anderson, D. Byrd, C. Hobbs III, E. Hogge, M. Iolt, and D. Tyler for their assistance in the field.

\section{Description of marsh environment}

The marshes and channels considered here lie behind a chain of barrier islands on the Atlantic side of Virginia's eastern shore peninsula, extending coastwise from the entrance to Chesapeake Bay to the Maryland boundary and beyond. Marshes and tidal flat embayments interconnected by numerous tidal channels occupy a belt some $6 \mathrm{~km}$ wide between the fastland and one of the barrier island inlets near Wachapreague, Virginia. The circulation within thc marsh complex here is almost completely tidal, there being only minor freshwater streams flowing into the area.

The predominant plant on the upper surface of the marshes is the cordgrass Spartina alterniflora which grows near the level of mean high water. The marsh is completely flooded during most spring tidal cycles with partial flooding during an average tide, excluding days when weather effects are dominant. Most of the water entering and leaving the inner marsh is conveyed within small winding channels that drain into the larger tidal channels scparating the marshes and leading to the ocean.

In the terminology of terrestrial stream classification (Horton 1945; Strahler 1952), the smallest marsh channel segments (those ending on the marsh) are designated first order, two first-order segments merging to form a second-order segment and so on. The trunk channel leaving the marsh proper is usually of fourth or fifth order; together with its tributaries, this segment then conveys the drainage from a definable area of marsh. Often, it appears that a given trunk channel extends all the way through the marsh so that the drainage network is not a closed system, but few of these are not, in fact, two distinct drainage basins having a common drainage divide. In general, there is communication between individual drainage basins only during times of complete marsh flooding.

Figure 1 shows a typical marsh channel network exposed at low tide. This system is about $400 \mathrm{~m}$ long, being $12 \mathrm{~m}$ wide near the mouth where the depth below the creek banks is about $1.5 \mathrm{~m}$. The three bridges crossing the trunk channcl were used as instrument platforms for flow measurements. Throughout most of an avcrage tidal cycle, water is confined to the highorder channel segments, but at the higher stages begins to enter pear-shaped, gently sloping basins or "pans" at the heads of 


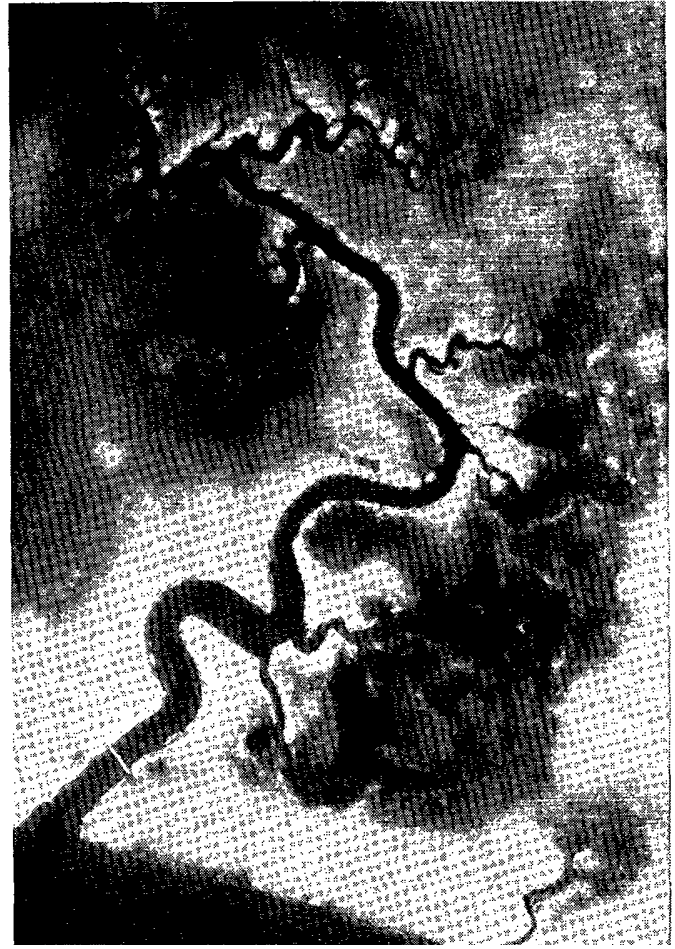

Fig. 2. Little Fool Creek during the initial stage of marsh flooding (MLW $+1.00 \mathrm{~m}$ ).

the first-order segments (Fig. 2). Finally, at maximum spring tide levels all of the marsh becomes flooded except for a few exposed levees about the trunk channel (Fig. 3). Mean tidal range at this location is about $1.22 \mathrm{~m}$.

\section{Tidal discharge model}

For a marsh channel system closed at one end, the continuity equation expressing discharge, $q$, in a flow cross section near the mouth can be written

$$
q=A \frac{\mathrm{d} h}{\mathrm{~d} t},
$$

where $q$ has the dimensions of volume per unit time, $A$ is the frec surface area inside the section, and $h$ is tidal stage. Herc time, $t$, is the independent variable although $A$ can also be a function of $h(t)$ cast as an intermediate variable. In using equation 1 as a model, it is assumed that: first, the

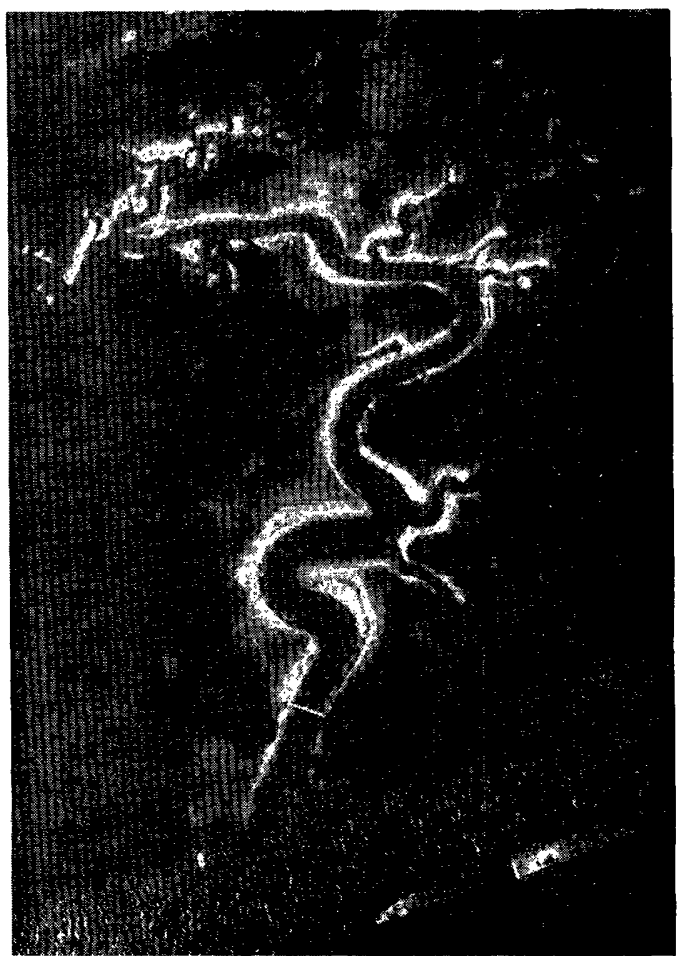

Fig. 3. Little Fool Creek during maximum flood stage ( $\mathrm{MLW}+1.25 \mathrm{~m}$ ).

channel is frictionless; second, the free surface is everywhere a level surface; third, the flow section near the mouth conveys all of the water entering or leaving the marsh drainage basin; and fourth, wind stress and inertial cffects are negligible.

The above assumptions are neccssary if one is to procced with a simple, flexible model. Nonlinear friction terms applicable to the varied surfaces encountered in the marsh would be highly complex. The second assumption is not unreasonable so long as the drainage network communicates freely with the occanic tide regime; the length of a marsh channel is very small compared to a tidal wavelength and assures that the tidal slope will be small within this system. The remaining assumptions may prove limiting during extreme marsh flooding, during very windy days, or during neap tide conditions when the tidal influence may be outweighed by other effects. 
Area-height relationship

As input to the discharge model, the area-height (hypsometric) relationship was investigated. Ragotzkie and Bryson (1955) were the first to present a curve of free surface arca plotted against tidal height for a marsh drainage system. Strahler (1952), however, had previously systematized hypsometric relationships for a variety of terrestrial drainage basins, using a mathematical expression

$$
y=\left[\frac{d-x}{x} \times \frac{a}{d-a}\right]^{z}
$$

where $d$ and $a$ are constants representing maximum and minimum area, $x$ and $y$ represent area and relative height, and $z$ is an exponential constant. Strahler demonstrated that most drainage configurations could be described by this formula which gencratcs a large family of curves depending on one's choice of $z$ and the factor $r$ $=a / d$, a constant controlling the degree of curvature.

In the present case, it is necessary to modify Strahler's formula since he dealt with basin areas above a given elevation whereas the present problem requires that portion of the total drainage area below a given height to match that of the water's free surface. The resulting expression is

$$
h^{\prime}=\left[1-\frac{A_{\max }-A}{A} \times \frac{A_{\min }}{A_{\max }-A_{\min }}\right]^{z},
$$

where $h^{\prime}=$ dimensionless tidal height and $A_{\text {max }}, A_{\text {min }}$ are the extreme free surface areas produced by the tide in a given drainage basin. The dimensionless height is defined as

$$
h^{\prime}=\frac{h-h_{\min }}{h_{\max }-h_{\min }}
$$

considering $h_{\mathrm{min}}, h_{\max }$ to be the limiting heights corresponding to the free surface extremes. For convenience in determining area as a function of height, equation 2 can be rewritten as

$$
A^{\prime}=\frac{r(1-G)}{r+G(1-r)} ; \quad G=\left(1-h^{\prime}\right)^{1 / z},
$$

in which $r=A_{\min } / A_{\max }$ and the dimensionless arca is

$$
A^{\prime}=\frac{A-A_{\min }}{A_{\max }-A_{\min }} .
$$

As input to equation 3, I measured free surface areas matched to tidal stage in the creek system shown in Fig. 1. Low altitude aerial photographs were taken near the vertical using black and white infrared film (35-mm Kodak high speed infrared) during various stages of a spring tide. Water areas appear black and the resolution of their margins is enhanced in positives made from this film. Three measured baselines, previously marked on the ground, were used to determine scale in the photographs and assess distortion effects. Tidal heights were obtained during the overflights by a recording tide gauge installed at the mouth of the creek. To verify location and height of true water margins at specific times, several control points at the apparent margins in the photographs were field identified and connected by levels to the tide gauge datum (mean low water). The agreement between true and apparent margins was good in comparison to the resolution permitted by the photographs. Finally, areas were measured with a planimeter, appropriately scaled, and matched with the corresponding height of tide.

The curvature factor, $r$, in equation 3 results immediately once estimates of $A_{\text {min }}$ and $A_{\max }$ are in hand. The exponent $z$ comes through trial and crror curve fitting to the remaining data, plotted in dimensionless form as $A^{\prime}$ and $h^{\prime}$. In my experience, estimation of the limiting values of height and area is reasonably straightforward because the convergence to these end points is fairly well defined for any given marsh basin. In contrast, the so-called bankfull stage, important in terrestrial stream hydraulics (Leopold and Maddock 1953; Wolman and Miller 1960), is not clearly defined in a marsh. A limitation imposed by equations 2 and 3 is that $A_{\text {nin }}$ must not be zero.

Figure 4 contains the data from my study (with $A_{\max }=80,200 \mathrm{~m}^{2}, h_{\max }=1.20 \mathrm{~m}, A_{\text {min }}$ 
$\left.=1,310 \mathrm{~m}^{2}, h_{\text {min }}=-0.2 \mathrm{~m}\right)$ and data based on the study by Ragotzkie and Bryson (1955) in which $A_{\max }=1.83 \times 10^{7} \mathrm{~m}^{2}, h_{\max }$ $=3.2 \mathrm{~m}, A_{\min }=1.7 \times 10^{6}, h_{\min }=0.0$ (mean low water). The Duplin River data, derived from charted contours and slope angle measuremonts, contain some scatter; they show, however, a surprising agreement in form with the curve selected for a system morc than two orders of magnitude smaller in actual size.

\section{Estimates of tidal prism}

By use of equation 1 , the total flood or ebb discharge can be found as

$$
Q=\int_{l_{l w}}^{l_{l w w}} q \mathrm{~d} t=\int_{l_{l \iota w}}^{h_{h w} w} A \mathrm{~d} h .
$$

Unfortunately, equation 3 does not lend itself to direct integration; however, either graphic or numeric integration techniques with a computer can be used. For example, one can measure the area under the curve in Fig. 4 between any high and low water stage and convert to true volume, $Q$, as defined by equation 4 , using

$$
\begin{aligned}
Q= & \left(A_{\max }-A_{\min }\right)\left(h_{\max }-h_{\min }\right) Q^{\prime} \\
& +A_{\min }\left(h_{\max }-h_{\min }\right) \Delta h^{\prime},
\end{aligned}
$$

where $Q^{\prime}=$ dimensionless volume (area under curve), and $\Delta h^{\prime}=$ dimensionless range. Any "overmarsh" volumes are accounted for by considering $A^{\prime}=1.0$ when $h^{\prime} \geqq 1.0$. Volume changes below the minimum stage can be neglected $\left(A^{\prime}=0\right.$ when $\left.h^{\prime} \leqq 0\right)$.

To provide independent verification of the model, I made a series of current measurements near the mouth of the creck (Fig. 1, lowest bridge) using a small ducted current speed sensor (Byrne and Boon 1973). Eight sensors were used in a fixed array within the cross section. Discharge values were then computed at 30-min intervals by summing the products of average velocity and area within transverse subsections of the flow (Boon 1973). Curves of discharge versus time were then integrated to obtain the total discharge, or tidal prism, estimates for flood and ebb. A number of measured prisms, along with the corresponding prisms predicted by the hyp-

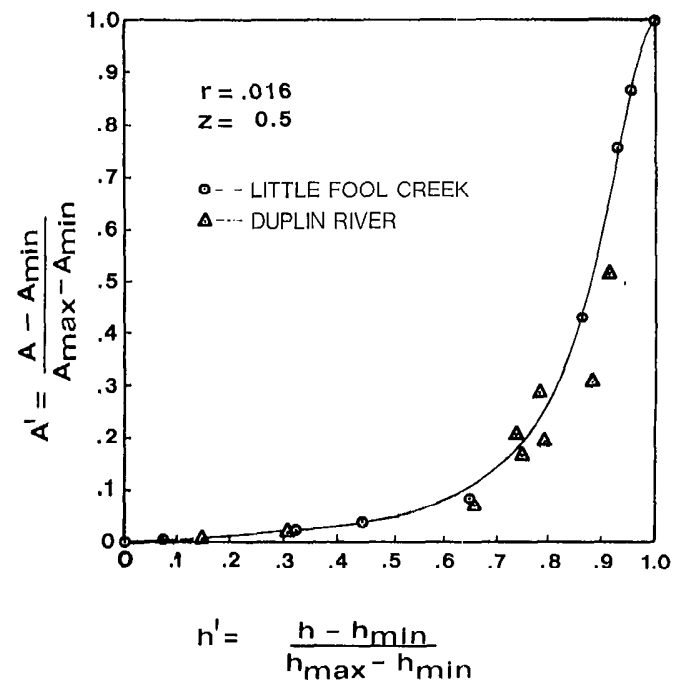

Fig. 4. IIypsographic curve based on arcaheight data obtained for Little Fool Creck. Data points for the Duplin River, Georgia, are from Ragotzkie and Bryson (1955).

sometric model, are presented in Table 1 for comparison.

\section{Time-varying tidal discharge}

Tidal effects

Tidal discharge can be predicted at discrete points in time, using equation 1 , provided that a suitable expression for the rate of change in tidal height, $\mathrm{d} h / \mathrm{d} t$, can be found. During an individual cycle, the tide can be modeled to a first approximation by

$$
h(t)=R_{0}+H \cos (\omega t-\phi),
$$

where $R_{0}=$ mean tide level, $H=$ observed tidal amplitude or semirange, $\omega=$ angular spced $=2 \pi / T$, where $T=12.42 \mathrm{hr}$, the semidiurnal period, and $\phi$ is the angular phase lag with respect to a selected time origin.

Although longer period constituents can be neglected when modeling a single semidiurnal cycle, there are important shallow water constituents or "ovcrtides" present in coastal and estuarine waterways that warrant considcration. Spectral analysis performed on a 43-day tidal record from the entrance to the study system indicated that, for heights measured in meters, an improved tidal formula would be 
Table 1. A comparison of total discharge values $\left(m^{3}\right)$ derived by the hypsometric model and by flow measurements at the entrance to Little Fool Creek. Phase: F-flood; E-ebb; R-residual. Tidal clatum is $M L W$.

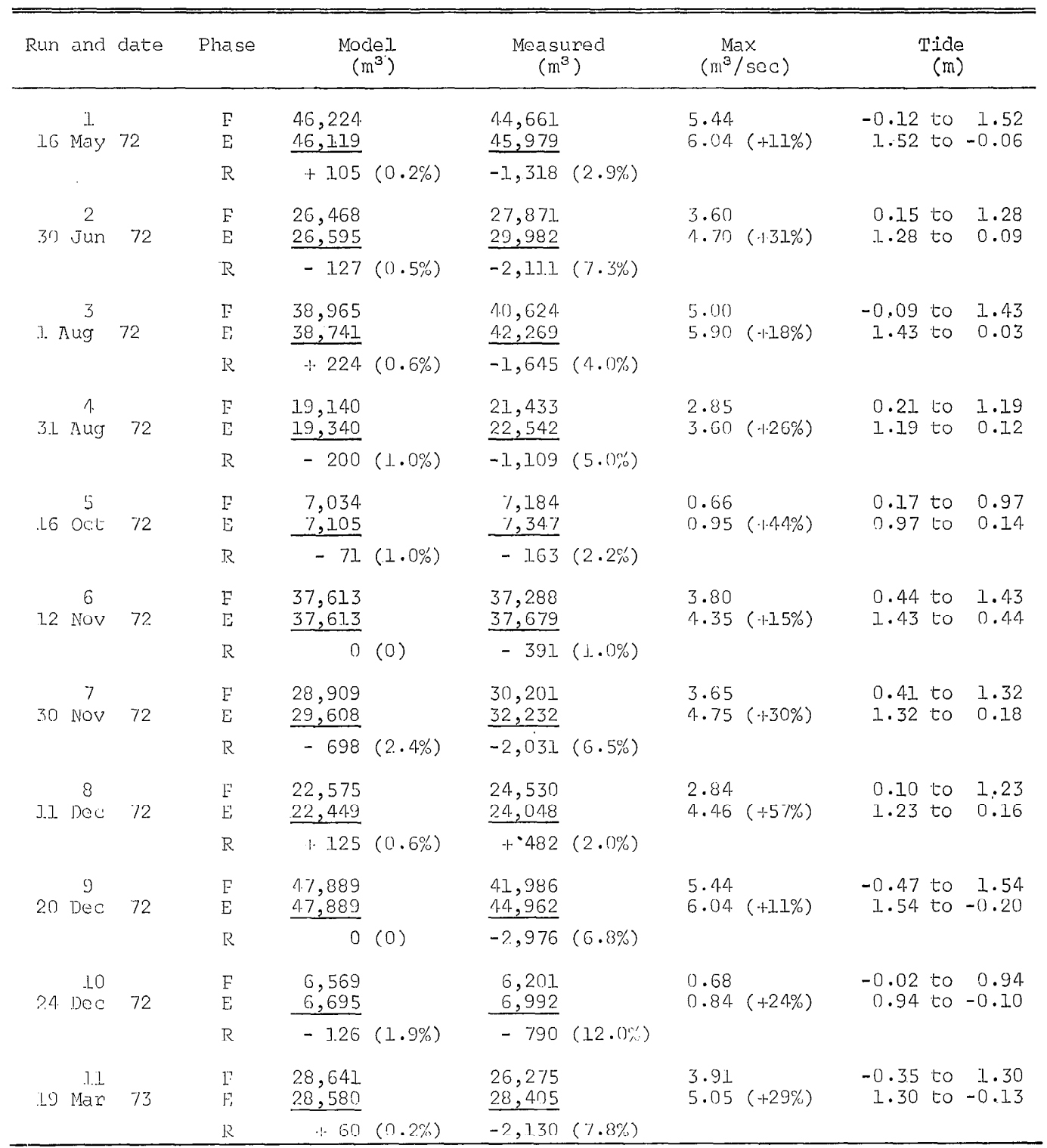

$$
\begin{aligned}
h(t)= & R_{0}+0.9 I I \cos \omega t \\
& +0.09 I I^{2} \cos \left(2 \omega t-37^{\circ}\right) \\
& +0.09 I I^{3} \cos \left(3 \omega t+16^{\circ}\right) .
\end{aligned}
$$

The third and fourth terms on the right side of the above equation are the quarter-diurnal and sixth-diurnal constituents whose amplitudes vary as the square and the cube, respectively, of the semidiurnal amplitude (Doodson and Warburg 1941). These two shallow water terms were largely responsible for an observed amplitude dependent distortion in local tide curves as reflected in the durations of rise and fall, the former excecding the latter by 0.3 to $0.6 \mathrm{hr}$ in monthly average value. 


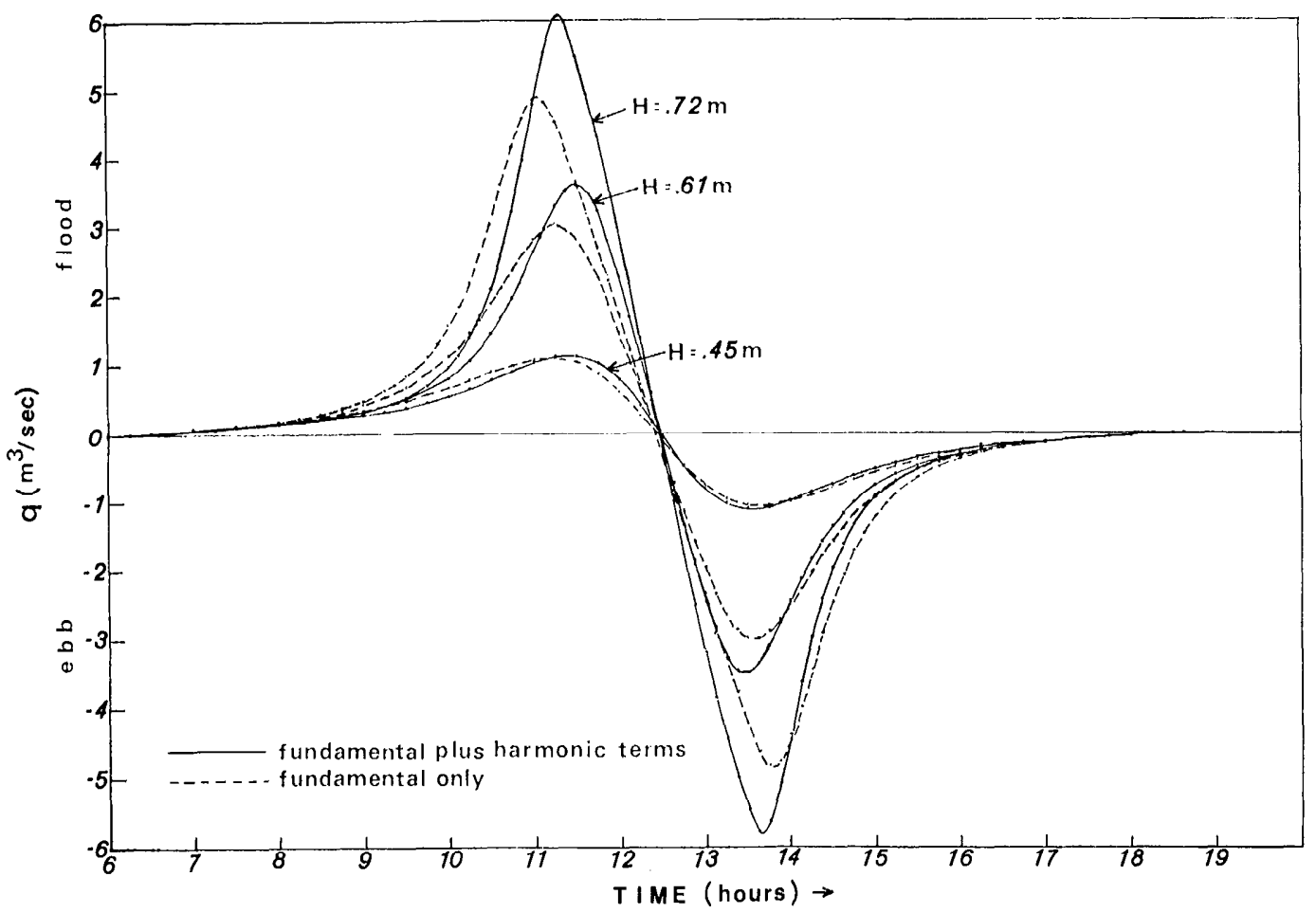

Fig. 5. Simulated tidal discharge curves for three different values of mean tidal amplitude, $I I$, at entrance to Little Fool Creck, showing influence of "overtides."

Differentiating equation 5, one obtains

$$
\begin{aligned}
\mathrm{d} h / \mathrm{d} t= & -0.94 H \omega \sin \omega t \\
& -0.18 H^{2} \omega \sin \left(2 \omega t-37^{\circ}\right) \\
& -0.27 H^{3} \omega \sin \left(3 \omega t+16^{\circ}\right) .
\end{aligned}
$$

Note that, as a result of differentiation, the shallow water terms have doubled and tripled, respectively, compared to their values in equation 5 .

Equation 5 is intended as a general model through which the shallow water tide effect can be illustrated. It therefore cannot be used to predict the tide accurately during any one cycle. One can determine the actual amplitudes and phases for each term in equation 5 corresponding to a measured tide through routine Fourier analysis (Jenkins and Watts 1968).

\section{Simulated discharge}

Equations 3, 5, and 6 provide the necessary input to a numerical model of tidal discharge as a function of time based on the continuity equation 1 . Numeric formulations such as the above are not difficult to program on a computer and can also be handled by many of the newer programable, desk-top calculators. Figure 5 shows a scries of curves produced by a calculator with plotter, using data derived for the test creck. The curves simulate typical cycles for neap, average, and spring range using $R_{0}=0.61 \mathrm{~m}$ (mean tide level) with equal low water heights at the ends of each cycle.

In Fig. 5 there is a pronounced asymmetry in each of the curves in the form of a shift of the maxima toward the time of high water slack. From Fig. 4 and the data in Table 1 it is clear that the marsh receives large volumes of water at the higher tidal stages. Moreover, most of the water does not enter the marsh until late in the cycle, just before the rise in water level begins to diminish prior to the high. Similarly, most of the volume within the marsh leaves within a short time once the tide 


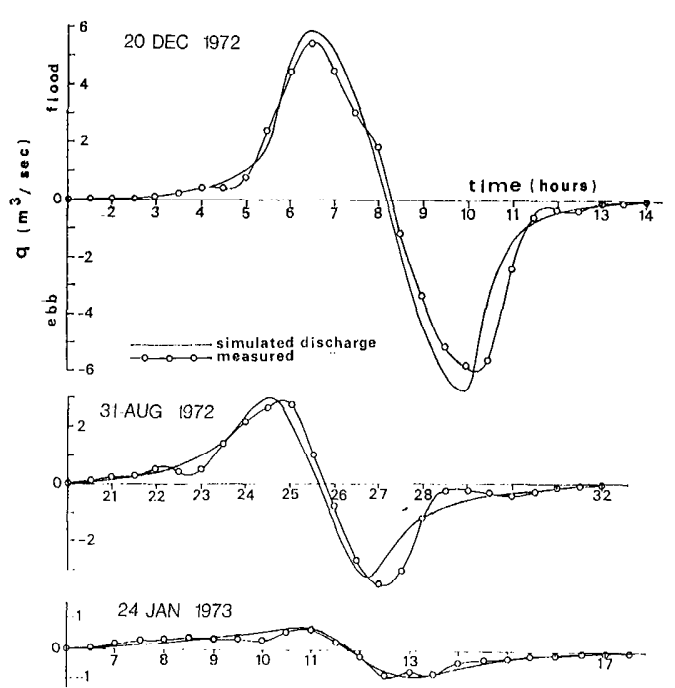

Fig. 6. A comparison of measured and simulated tidal discharge curves during spring, average, and neap tide field experiments conducted at entrance to Little Fool Creek.

level begins to fall. Assuming that all of this flow is conveyed by the trunk channel, it is obvious that the discharge curve in a section of that channel must be strongly distorted. Less obvious but clcarly implied in Fig. 5 is an added distortion and an increase in peak discharge duc to the presence of shallow water constituents, especially noticcable under spring tide conditions.

\section{Measured discharge}

Figure 6 gives examples of the discharge curves obtained in the test crcek from actual flow measurements at a cross section. The three solid curves are representative of flows measured during spring, average, and neap cycles; the dashed curves are simulations produced by the discharge model using amplitude and phase information derived separately for each tide through Fourier analysis, up to and including the eighth-diurnal constituent.

In general, Fig. 6 shows a fair agreement between measured and simulated flows, particularly as regards the degree of asymmetry present in each case. The measured curves, plus others not shown, typically

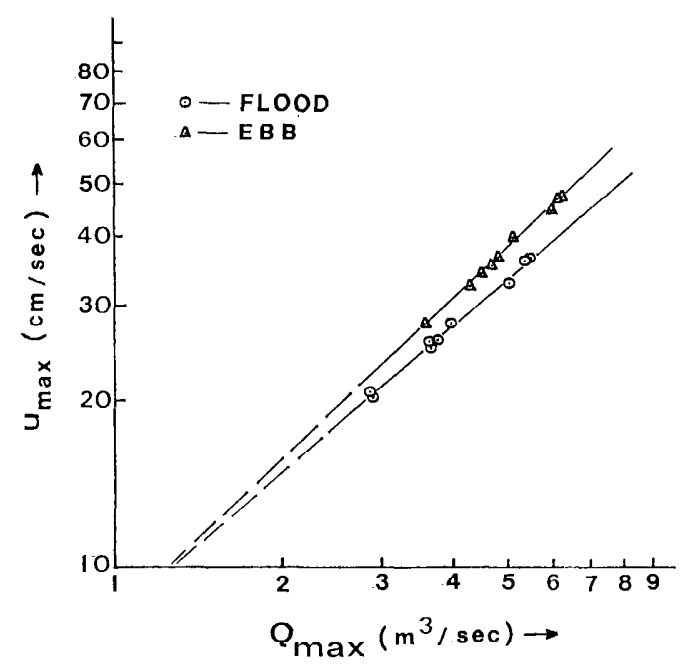

Fig. 7. A plot of measured discharge and areaaveraged current speed maxima obtained at entrance to Little Fool Creck.

include short period perturbations, probably due to inertial effects arising in closed channels that experience reversing flows. Such effects undoubtedly cause the local free surface to depart slightly from the level surface assumed in the model at certain times during each cycle. During neap tides, wind effects are often dominant so that discharge becomes erratic.

An additional feature noted in each of the measured flows is a persistent difference in the peak discharge for flood and ebb (Table 1). Peak ebb discharge exceeds that of flood by more than $50 \%$ in some cycles whereas the measured volumes entering and leaving the marsh normally differ by less than $7 \%$, or within the limit of expected measurement error (Boon 1974). The peak discharge levels predicted by the model do not reflect a difference of this magnitude.

\section{Discharge-current speed}

The asymmetry seen in the measured curves of time-varying discharge is mirrored closely by curves of current speed. This result is to be expected since the two quantities differ by the factor of flowsectional area which increases uniformly with tidal height. Myrick and Leopold 
(1963) demonstrated that discharge and current speed at a station are related by a simple power law of the form $u=k Q^{m}$ where $k$ and $m$ are dimensionless constants. An interesting footnotc to their work results if one considers only the peak values in each cycle.

In Fig. 7, measured maximum discharge values $\left(q_{\mathrm{max}}\right)$ are plotted against maximum current speeds $\left(u_{\max }\right)$, the latter computed as spatially weighted averages from eight current meters operating simultaneously in the flow section. Adopting the power law convention, good correlation results between $q_{\max }$ and $u_{\max }$ values for a number of tides having varying combinations of range and mean water level; however, the slopes of the fitted curves for flood and ebb ensembles are significantly different. Figure 7 suggests that there is an additional effect, porhaps a friction related one, that accounts for the more rapid increase in $u_{\max }$ with increasing $q_{\max }$ in the case of ebb flows. Similarly, if all tides over a year were to be considered, the mean levels of $q_{\max }$ and $u_{\max }$ apparently would both be greater for ebb flows, although more data are needed to confirm this interpretation.

\section{Discussion}

Tidal discharge asymmetries occur in tidal marsh creeks as a consequence of drainage basin morphology and storage characteristics in conjunction with prevailing tidal range and stage. In other parts of the marsh-lagoon complex, such as the drainage channels found on exposed mud flats, a different set of morphologic and tidal conditions can be expected. Postma's (1.961) observation that tidal flat channels demonstrate a flow asymmetry which is out of phase by half a tidal wavelength from the asymmetry here described for marsh channels does not, therefore, conflict with my results. Moreover, the interesting theory by Groen (1967) showing how the direction of residual suspended sediment transport may depend on flow asymmetry has added implications insofar as transport within marsh channels is concerned.

Data collected and reported elsewhere
(Boon 1973, 1974) indicated a predominantly seaward net transport of suspended sediment in the system shown in Fig. 1. However, other processes besides the flow asymmetry were found to be at work which caused both the direction and the magnitude of the residual to vary seasonally. Among these were water temperature, which showed a positive association with seasonal suspended sediment levels, and an annual cycle in monthly mean sea level due to a steric effect (Pattullo et al. 1955), which produces seasonal variations in the volume of water flooding the marsh. Lcss information exists on transient effects, such as the creation of horizontal gradients of suspended sediment between bay and marsh by the action of wind waves.

Future studies in tidal marshes by geologists and biologists may require estimates of transport of suspended solids in dissolved and particulate, organic and inorganic form. An understanding of the temporal and spatial relationships in tidally induced flows is highly germane to this work. However, the determination of timevarying tidal discharge by mcans of an area-height model, rather than by direct flow measurements, is not recommended for the calculation of net transport. The net movement of suspended matter in marsh channels has bcen the subject of little basic research to datc, particularly insofar as flow measurements are concerned. Sectional flow measurements obtained with precision current meters can be expected to yicld better accuracies than those which the assumptions inherent in an area-height model can support, and on which confidence in the present model indeed depends. In other applications, such as the hindcasting of total flood or ebb discharge (tidal prism) and long term prism distributions from continuous tide data, the areaheight model can be very useful.

\section{References}

Boon, J. D. 1973. Sediment transport processes in a salt marsh drainage system. Ph.D. thesis, College of William and Mary, Williamsburg, Va. 226 p. 
1974. Optimized measurements of discharge and suspended sediment transport in a salt marsh drainage system, in press. In Symp. Int., "Relations sedimentaircs entre estuaires et plateaux continentaux." Inst. Geol. du Bassin d'Aquitaine, Bordeaux.

Byrne, R. J., ANd J. D. Boon. 1973. An inexpensive, fast response current speed indicator. Chesapeake Sci. 14: 217-219.

Doodson, A. T., AND H. D. Wariburc. 1941. Admiralty manual of tides. Admiralty Hydrogr. Office, London. $270 \mathrm{p}$.

Groen, P. 1967. On the residual transport of suspended matter by an alternating tidal current. Neth. J. Sea Res. 3: 564-574.

Honton, R. E. 1945. Erosional development of streams and their drainage basins; hydrophysical approach to quantitative morphology. Geol. Soc. Am. Bull. 56: 275-370.

Jenkins, G. M., and D. G. Whtts. 1968. Spectral analysis and its applications. HoldenDay.

LeOPOLD, L. B., AND T. MADDOCK. 1953. The hydraulic geometry of stream channels and some physiographic implications. U.S. Geol. Surv. Prof. Pap. 252. 57 p.

Mesde, R. II. 1969. Landward transport of bottom sediments in estuaries of the Atlantic Coastal Plain. J. Sediment. Petrol. 39: 222234.

—_ 1974. Net transport of sediment through the mouths of estuaries: seaward or landward?, in press. In Symp. Int., "Rclations sedimentaires entre estuaires et plateaux continentaux." Inst. Gcol. dı Bassin d'Aquitaine, Bordcaux.

Myrick, R. M., AND L. B. Leopold. 1963. Hy- draulic geometry of a small tidal estuary. U.S. Geol. Surv. Prof. Pap. 422-13. 18 p.

Oostdam, B. L. 1971. Suspended sediment transport in Delaware Bay. Ph.D. thesis, Univ. Delawarc, Newark. 316 p.

Pattullo, J., W. Munk, R. Revelle, and E. StroNG. 1955. The seasonal oscillation in sea level. J. Mar. Res. 14: 88-155.

Pestrong, R. 1965. The development of drainage patterns on tidal marshes. Stanford Univ. Publ. Geol. Sci., Tech. Rep. 10. 87 p.

Postma, H. 1954. Hydrography of the Dutch Wadden Sea. Arch. Neerl. Zool. 10: 405511.

2. 1961. Suspended matter and Secchi disc visibility in coastal waters. Neth. J. Sea Res. 1: 359-390.

- 1967. Sediment transport and sedimentation in the estuarine environment, p. 158179. In G. H. Lauff [ed.], Estuaries. Am. Assoc. Adv. Sci. Publ. 83.

RagotzkIE, R. A., AND R. A. Bryson, 1955. Hydrography of the Duplin River, Sapelo Island, Gcorgia. Bull. Mar. Sci. Gulf Carib. 5: 297314.

Strairlei, A. N. 1952. Hypsometric (area-altitude) analysis of crosional topography. Geol. Soc. Am. Bull. 63: 1117-1142.

Van Stiraten, L. M. J. U., and P. H. Kuenen. 1957. Accumulation of fine-grained sediments in the Dutch Wadden Sca. Gcol. Mijnbouw 19: 329-354.

Wolman, M. G., and J. P. Miller. 1960. Magnitude and frequency of forces in geomorphic processes. J. Geol. 68: 54-74.

Submitted: 29 March 1974 Accepted: 10 October 1974 